\title{
Safety and Efficacy of a Fully Covered Self-Expandable Metallic Stent in Benign Airway Stenosis
}

\author{
Marc Fortin Yves Lacasse Xavier Elharrar Rachid Tazi-Mezalek \\ Sophie Laroumagne Julien Guinde Philippe Astoul Hervé Dutau \\ Department of Thoracic Oncology, Pleural Disease, and Interventional Pulmonology, North Hospital, \\ Marseilles, France
}

\section{Keywords}

Fully covered self-expandable metallic stent · Benign

airway stenosis · Safety · Efficacy

\begin{abstract}
Background: The use of self-expandable metallic stents (SEMS) in benign airway disease was the object of a boxed warning from the United States Food and Drug Administration in 2005 due to the risk of stent-related complications and difficulties associated with their removal. Third-generation fully covered SEMS have been commercialized since this warning and theoretically should not present the same difficulties associated with removal as they cannot become embedded in the airway mucosa. Objectives: We aimed to examine the safety and efficacy of a specific third-generation SEMS, the Silmet stent. Methods: We reviewed the records of all patients treated for benign airway stenosis with third-generation Silmet SEMS from January 2011 to December 2015 at the North Hospital of Marseilles, France. Results: Forty SEMS were inserted in 30 patients over this period. Twenty (50.0\%) stents were removed because of stentrelated complications after a median of $77.0 \pm 96.6$ days (migration $32.5 \%$, granulation tissue formation $7.5 \%$, sub-
\end{abstract}

(c) 2017 S. Karger AG, Basel jective intolerance $5.0 \%$, mucus plugging $2.5 \%$, laryngeal edema $2.5 \%$ ). There were no cases of stent-related mortality. All complications were managed successfully endoscopically. Thirty-six stents (90.0\%) were removed successfully after a median of $122.0 \pm 113.2$ days without any complications. The clinical success rate of stent treatment was $40.7 \%$. Conclusion: Third-generation SEMS are a safe treatment option for complex benign airway stenosis, but complications requiring stent removal are frequent. Further studies are needed to compare the performance of third-generation SEMS and silicone stents in benign airway stenosis.

(c) 2017 S. Karger AG, Basel

\section{Introduction}

Endoscopic treatment of airway stenosis has gained popularity over the last decades. Initial treatments mainly involved dilatation and insertion of silicone stents [1]. In the late 1980s, the use of modified vascular metal stents in the airways was attempted, with unacceptable complication rates [2]. Subsequently in the 1990s, self-expandable metallic stents (SEMS) designed for the airways obtained better initial clinical results and acceptable complication

\section{KARGER}

E-Mail karger@karger.com

www.karger.com/res
Marc Fortin

Institut Universitaire de Cardiologie et de Pneumologie de Québec 725 Chemin Ste-Foy

Quebec City, QC G1V 4G5 (Canada)

E-Mail marc.fortin.4@ulaval.ca 
Fig. 1. Silmet self-expandable metallic

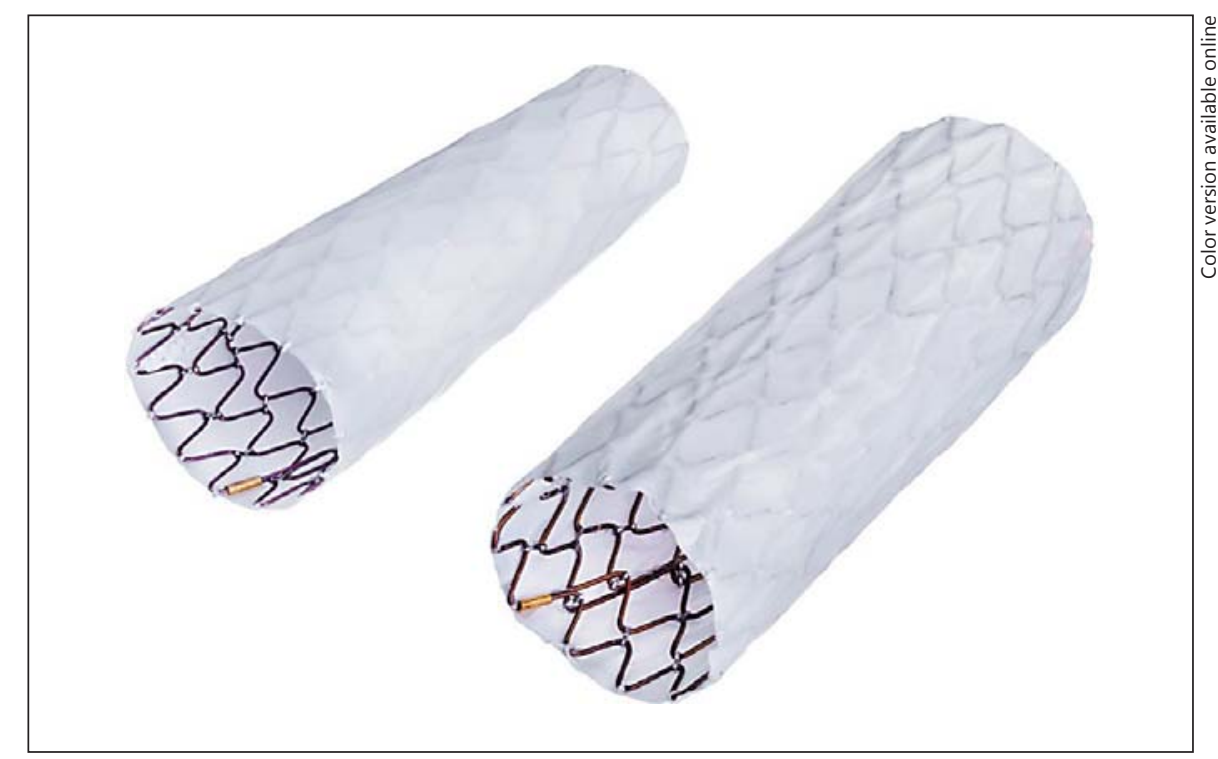

rates [3]. The possibility to deploy SEMS with the assistance of flexible bronchoscopy, guidewires, and fluoroscopy, without the use of rigid bronchoscopy required for the deployment of silicone stents, led to a more frequent use of airway stents. Initial publications involved a variety of stents and pathologies [3-5], but as experience with SEMS grew, long-term complications and difficulties of removal in patients with prolonged survival became apparent even with partially covered stents $[6,7]$. This culminated in a boxed warning for the use of SEMS in benign tracheal disease from the United States Food and Drug Administration in 2005 [8]. This warning focused on patients with benign disease due to the prolonged survival in this group, allowing time for complications to develop and cause significant clinical impairment [9].

Three generations of metallic airway stents exist. The first generation is composed of uncovered balloon-expandable metallic stents, the second of partially covered or uncovered SEMS, and the third of fully covered SEMS. Third-generation SEMS were introduced to solve the problem of metallic stent removal. Despite almost a decade of experience with third-generation SEMS, few data have been published on their efficacy, complications, and removability. Marchese et al. [10] recently published their experience with 52 patients obtaining clinically significant symptomatic improvement in all but 1 patient with an acceptable complication rate (migration $13.4 \%$, granulation tissue formation $3.8 \%$, infections $5.7 \%$, obstruction due to tumor outgrowth $15.0 \%$ ) and successful removal in all 7 cases where it was required. This experience al- most exclusively included malignant airway obstructions (49/52), a situation where second-generation SEMS had previously also performed well. The only available reports of the performance of third-generation SEMS in benign airway disease include a series of 17 patients published by Dooms et al. [11] shortly after the appearance on the market of these stents, demonstrating an unacceptable complication rate at 12 weeks (stent migration $60 \%$, stent fracture $15 \%$, stent shriveling $10 \%$ ) as well as other small series of post lung transplantation anastomotic strictures treated mainly with AERO stents (Merit Medical Systems, South Jordan, UT, USA) [12-14]. Our clinical experience with fully covered third-generation SEMS in benign airway stenosis is larger than any other previously published series to our knowledge; hence, we decided to review it to evaluate the safety and efficacy of third-generation SEMS in benign airway disease.

\section{Methods}

We reviewed the charts and electronic records of all patients treated with fully covered Silmet (Novatech, La Ciotat, France) (Fig. 1) SEMS for benign airway stenosis from January 2011 to December 2015 at the Hôpital Nord de l'Assistance Publique des Hôpitaux de Marseille.

Information obtained from chart and electronic record review include age, sex, diagnosis, site of airway disease, simple versus complex stenosis, previous treatments, cause of previous treatment failure, type and dimensions of stent inserted, technical success of stent insertion, procedural complications, stent dwell time, necessity of stent removal, cause of stent removal, complications 
of stent removal, stent-related complications (stent migration, stent fracture, granulation tissue formation, mucus plugging requiring intervention, stent shriveling, subjective stent intolerance), time to complication, and necessity of new intervention after stent removal. Stenosis with an element of malacia was classified as complex [15]. The usual follow-up for stents in benign airway disease at our institution includes visits at 1, 6, and 12 months, then annually. No systematic follow-up bronchoscopy was performed unless the patient was symptomatic. Stent removal was attempted after 6-12 months unless the patient was felt to be at too high risk of stenosis recurrence.

An intervention was classified as successful if a stent removal trial was followed by a favorable evolution without the need for further intervention after a follow-up of at least 1 year or if a stent was left in place indefinitely without complication. The clinical success rate was calculated as the number of patients who underwent a successful intervention divided by the total number of patients, excluding patients who died of causes unrelated to their airway stenosis and patients who had a stent inserted as a bridge to surgery.

All procedures were performed under general anesthesia using rigid bronchoscopy and direct visualization during stent positioning. Institutional research ethics board approval was obtained for this retrospective study.

Descriptive statistics (mean, median, standard deviation, range) as well as the Fisher exact test were used to compare the clinical success rate between different etiologies of stenosis, site of stenosis, and treatment-naive versus non-treatment-naive patients. $p$ values $<0.05$ were considered to be statistically significant.

\section{Results}

Forty Silmet stents were implanted in 30 patients with benign airway stenosis over the study period. No patient had multiple stenoses, but 7 patients had multiple treatment attempts with SEMS. The patients' baseline characteristics are summarized in Table 1 . All 30 patients had complex airway stenosis. The most frequent etiologies of airway stenosis were post tracheostomy and post lung transplantation. Sixteen (53.3\%) patients had previously been treated with 20 silicone stents: 11 (55.0\%) migrated, $7(35.0 \%)$ formed granulation tissue requiring intervention, $1(5.0 \%)$ caused laryngeal edema requiring urgent removal, and 1 (5.0\%) was removed prematurely for unclear reasons on chart review. Ten (33.3\%) patients were previously treatment-naive.

All 40 stent placement procedures were technical successes and there were no procedural complications. The stent characteristics are described in Table 2. Twenty $(50.0 \%)$ stents were removed because of stent-related complications after a median of $77.0 \pm 96.6$ days. Thirteen $(32.5 \%)$ stents migrated, $3(7.5 \%)$ caused formation of granulation tissue requiring intervention, $2(5.0 \%)$ caused subjective intolerance (cough, chest discomfort), 1 (2.5\%)
Table 1. Patients' baseline characteristics

\begin{tabular}{lc}
\hline Age, years & $47.5 \pm 17.1$ \\
Male sex & $22(73.3 \%)$ \\
Stenosis etiology & \\
$\quad$ Post tracheostomy & $16(53.3 \%)$ \\
$\quad$ Post lung transplantation & $8(26.7 \%)$ \\
$\quad$ Post intubation & $4(12.5 \%)$ \\
$\quad$ Idiopathic & $2(6.7 \%)$ \\
Previous treatments & \\
$\quad$ Treatment-naive & $10(33.3 \%)$ \\
Mechanical dilatation & $4(13.3 \%)$ \\
Silicone stent & $16(53.3 \%)$
\end{tabular}

Values are presented as mean \pm standard deviation or $n(\%)$.

Table 2. Stent characteristics

\begin{tabular}{lc}
\hline Length, mm & $50(20-70)$ \\
Diameter, mm & $16(10-20)$ \\
Site & \\
$\quad$ Trachea & $24(60.0 \%)$ \\
$\quad$ Left mainstem bronchus & $12(30.0 \%)$ \\
Right mainstem bronchus & $1(2.3 \%)$ \\
$\quad$ Bronchus intermedius & $3(7.7 \%)$ \\
\hline
\end{tabular}

Values are presented as median (range) or $n(\%)$.

was repeatedly plugged with mucus requiring bronchoscopy, and $1(2.5 \%)$ was removed urgently $24 \mathrm{~h}$ after deployment because of laryngeal edema. There were no cases of stent shriveling or fracture. No mortality was associated with stent complications. All complications were managed endoscopically with success. In the case of laryngeal edema, the stent was removed and a tracheostomy tube was reinserted as prior to the airway stent insertion procedure. Nine of the $10(90.0 \%)$ patients who had stent migration had a history of stent migration when previously treated with silicone stents.

Thirteen (43.3\%) patients had an elective stent removal trial after a median dwell time of $223.5 \pm 95.8$ days. Nine (69.2\%) patients required no further intervention on follow-up, and 4 (30.8\%) had symptom recurrence: 2 (15.4\%) were referred for surgical treatment, while $2(15.4 \%)$ had a new SEMS inserted (Fig. 2). One (3.3\%) patient had a stent inserted in an emergency situation as a bridge to surgery which was removed during an elective surgery 35 days later. Two $(6.7 \%)$ patients had their stents left in place indefinitely because they were judged to be at high risk of relapse if their stent was removed and suffered no $\begin{array}{ll} & \text { Respiration 2017;93:430-435 } \\ \text { DOI: } 10.1159 / 000472155\end{array}$
Fortin/Lacasse/Elharrar/Tazi-Mezalek/ Laroumagne/Guinde/Astoul/Dutau 


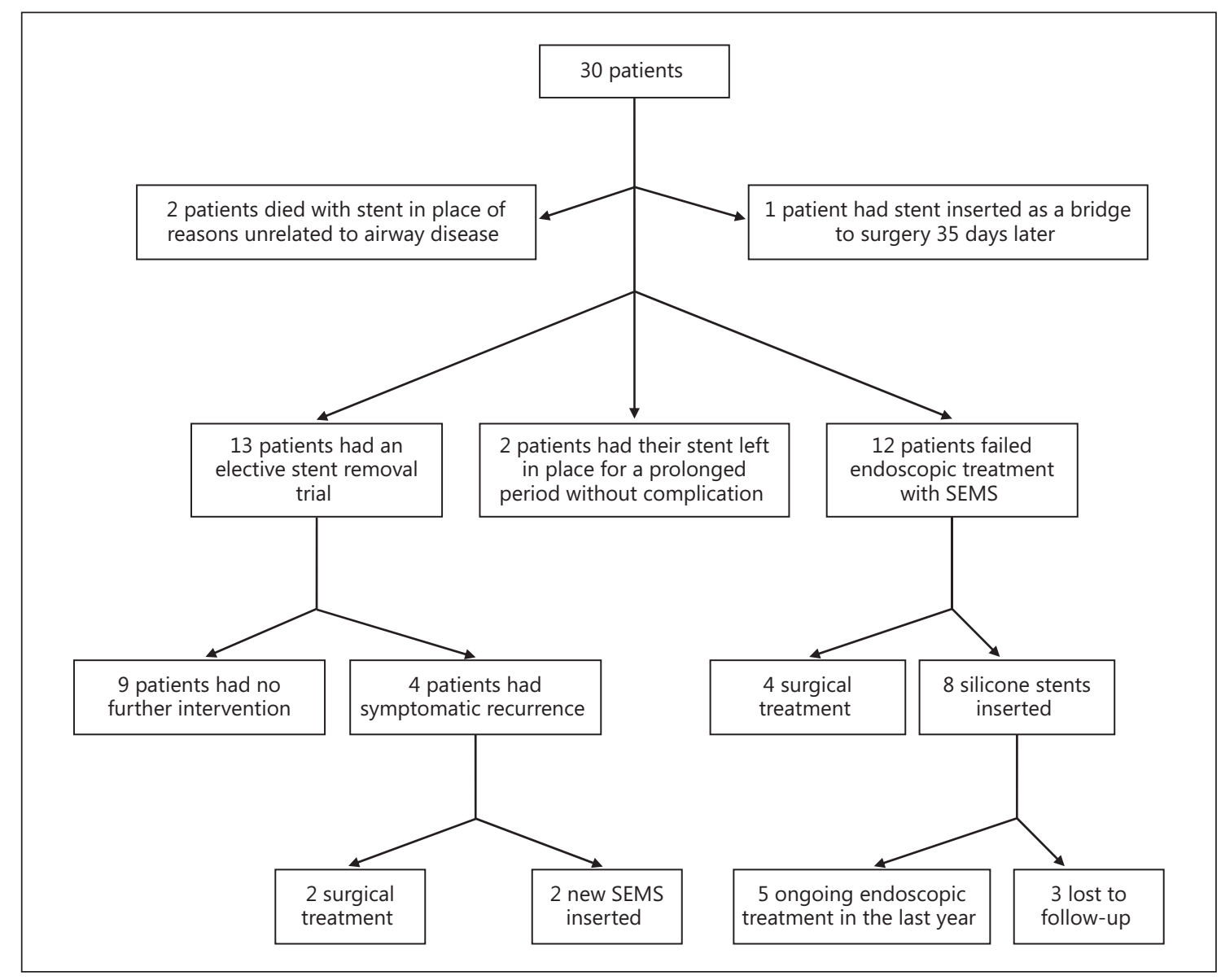

Fig. 2. Outcome of patients treated with self-expandable metallic stents (SEMS).

complications after a follow-up of 433 and 455 days, respectively. Two patients $(6.7 \%)$ died of unrelated causes with their stent in place without any stent-related complication. No patients were lost to follow-up with an SEMS in place. The clinical success rate of SEMS treatment was $11 / 27$ (40.7\%). It did not differ statistically significantly according to type of stenosis, site of stenosis, or presence or absence of previous treatments $(p=0.39, p=0.55$, and $p=0.37$, respectively).

Six $(20.0 \%)$ patients eventually went on to have surgical resection at our institution after failure of endoscopic treatment including SEMS placement. No patient was judged not to be a surgical candidate because of the extent of the disease or tracheal damage caused by endoscopic treatment. Five $(83.3 \%)$ surgeries were successful without any complication noted, and $1(16.7 \%)$ patient had a restenosis at the anastomotic site. Eight patients (26.7\%) underwent further endoscopic treatments with silicone stents: 3 (37.5\%) were lost to follow-up, and 5 (62.5\%)

Self-Expandable Metallic Stents in Benign Airway Stenosis were treated endoscopically in the last year and are actively followed in our service.

\section{Discussion}

This is the largest series to date documenting the safety and removability of fully covered SEMS in benign airway stenosis. The use of SEMS in benign airway disease was the object of a boxed warning from the United States Food and Drug Association in 2005 [8], due to complications associated with their removal and their risk of precluding patients from receiving future alternative therapies such as tracheal surgical procedures $[16,17]$. Stent removal was possible in all cases when necessary in our population without any complications, which was to be expected since these stents are fully covered and cannot become embedded into the mucosal wall as the previous generations of airway stents, which were uncovered or 
partially covered. Endoscopic treatment with a fully covered SEMS did not preclude any patient from receiving alternative therapies, but only 6 patients were referred for surgical treatment of their stenosis.

We report a complication rate of $50.0 \%$ with thirdgeneration SEMS and no stent-related mortality. This figure is lower than that previously reported by Dooms et al. [11], which may be explained by a difference in experience with the use of third-generation SEMS. We had been using these stents for 5 years prior to the beginning of the study period, while Dooms et al. published their initial experience with a technology which was novel in 2006. With any new stent a learning curve is mandatory, and we cannot always draw conclusions from initial experiences. Experience is especially important for stent sizing, as undersizing may lead to migration, while oversizing may lead to fracture and metal fatigue. Dooms et al. also included several different third-generation SEMS in their study, and all third-generation SEMS may not be equal in all situations, as their fabrication methods and composition differ [15]. This is the reason why we included only one stent model in our series. As an example, certain stents demonstrate less elongation on compression and hence will undergo less stress, putting them at lower risk of cover damage and fracture. Although important, our complication rate can be considered acceptable when put into perspective with the previous failure of other treatment options in the majority of the study population, the successful endoscopic management of all complications, and the absence of stent-related mortality or major complications. All patients had complex airway stenosis unlikely to resolve without stent placement, as previously demonstrated $[18,19]$. Sixteen $(53.3 \%)$ patients had previously been treated with silicone stents and treatment had failed in all cases because of stent-related complications. The largest series of endoscopic treatment of benign airway stenosis with silicone stents demonstrated a complication rate of $30.1 \%$ [20], which is lower than in our series with covered SEMS, but complication and treatment success rates would likely have decreased if SEMS had been used routinely at our institution as a firstline treatment of complex benign airway stenosis.

SEMS present theoretical advantages over silicone stents which may be of interest in the treatment of benign airway stenosis. SEMS are available in diameters up to $20 \mathrm{~mm}$, whereas the largest diameter of silicone stent available is $18 \mathrm{~mm}$. SEMS can also be customized to larger diameters if needed, but larger silicone stents would pose a problem to insert as the largest instruments available for their deployment would not suffice [21]. One must also consider the wall thickness of silicone stents $(1.0-1.5 \mathrm{~mm})$, making, in our experience, a 20-mm SEMS the equivalent of an 18-mm silicone stent. This difference may be of clinical interest in the treatment of tracheal disease, where the largest diameter of silicone stent commercially available may be insufficient, increasing the risk of migration. Our previous work showed a lower risk of migration with Silmet stents than with silicone stents in dynamic A-shape tracheal stenosis, a situation where large tracheal stents are needed [22]. In our experience, certain SEMS, such as Silmet stents, also have less axial stiffness than silicone stents and adapt better to the shape of tortuous airways.

As previously mentioned, SEMS can be inserted using flexible bronchoscopy and under fluoroscopic guidance but, at our institution, all SEMS are placed during rigid bronchoscopy under direct vision. To our knowledge, no previous studies have compared these methods, but we feel that rigid bronchoscopy is more efficient. It allows the operator to dilate the airway stenosis using the rigid bronchoscope and to treat potential complications more efficiently. It also allows easier removal of airway stents if necessary. We also feel that direct vision allows more precise positioning and adjustment of the stent's position after it has been released.

There are limitations to this study. First, the studied population was small, although this is the largest experience yet published with SEMS in benign airway stenosis. Second, we could not directly compare the complication and treatment success rates between SEMS and silicone stents in our population because failure of previous silicone stent treatment was not necessary for treatment with SEMS, although the majority of patients included had previously failed treatment with silicone stents and because patients in whom silicone stent treatment was a success were not included in this study. We stress that comparing the performance of SEMS and silicone stents was not the objective of this study, which was to demonstrate the safety of Silmet stents in benign airway disease and, secondarily, their efficacy. Third, complications may have been missed due to the retrospective nature of the study and the absence of systematic follow-up bronchoscopy. On the other hand, we feel that systematic follow-up bronchoscopies detect mainly clinically insignificant complications and that the goal of stenting is symptom palliation, which can be evaluated clinically. Finally, we did not have formal symptomatic and quality of life follow-up questionnaires available, hence the clinical success rate of SEMS treatments was based on endoscopic aspect after stent positioning and subjective physician questionnaire on followup without the use of formal measurement tools. 


\section{Conclusion}

We conclude that Silmet SEMS are a safe treatment option for benign airway stenosis. Further studies are needed to increase the published experience with fully covered SEMS in benign airway stenosis, to compare the performance of third-generation SEMS and silicone stents, and to improve our understanding of stenosis characteristics (e.g., shape or location), which should favor the placement of one stent compared to another.

\section{References}

1 Dumon JF: A dedicated tracheobronchial stent. Chest 1990;97:328-332.

2 Rousseau H, Dahan M, Lauque D, Carré P, Didier A, Bilbao I, Herrero J, Blancjouvant F, Joffre F: Self-expandable prostheses in the tracheobronchial tree. Radiology 1993;188:199203.

3 Dasgupta A, Dolmatch BL, Abi-Saleh WJ, Mathur PN, Mehta AC: Self-expandable metallic airway stent insertion employing flexible bronchoscopy: preliminary results. Chest 1998;114:106-109.

4 Madden BP, Datta S, Charokopos N: Experience with Ultraflex expandable metallic stents in the management of endobronchial pathology. Ann Thorac Surg 2002;73:938-944.

5 Saad CP, Murthy S, Krizmanich G, Mehta AC: Self-expandable metallic airway stents and flexible bronchoscopy: long-term outcomes analysis. Chest 2003;124:1993-1999.

6 Colreavy MP, Walsh MA: Nitinol tracheobronchial stents: a word of caution. Laryngoscope 2000;110:1070.

7 Lunn W, Feller-Kopman D, Wahidi M, Ashiku S, Thurer R, Ernst A: Endoscopic removal of metallic airway stents. Chest 2005; 127 : 2106-2112.

8 FDA public health notification: complications from metallic tracheal stents in patients with benign airway disorders, 2005 .

9 Chung FT, Chen HC, Chou CL, Yu CT, Kuo $\mathrm{CH}$, Kuo HP, Lin SM: An outcome analysis of self-expandable metallic stents in central airway obstruction: a cohort study. J Cardiothorac Surg 2011;6:46.
10 Marchese R, Poidomani G, Paglino G, Crimi C, Lo Nigro C, Argano V: Fully covered selfexpandable metal stent in tracheobronchial disorders: clinical experience. Respiration 2015;89:49-56.

11 Dooms C, De Keukeleire T, Janssens A, Carron K: Performance of fully covered self-expanding metallic stents in benign airway strictures. Respiration 2009;77:420-426.

12 Fernandez-Bussy S, Akindipe O, Kulkarni V, Swafford W, Baz M, Jantz MA: Clinical experience with a new removable tracheobronchial stent in the management of airway complications after lung transplantation. J Heart Lung Transplant 2009;28:683-688.

13 Shin JH, Song HY, Ko GY, Shim TS, Kim SW, Cho YK, Ko HK, Kim YJ, Yoon HK, Sung KB: Treatment of tracheobronchial obstruction with a polytetrafluoroethylene-covered retrievable expandable nitinol stent. J Vasc Interv Radiol 2006;17:657-663.

14 Tan JH, Fidelman N, Durack JC, Hays SR, Leard LL, Laberge JM, Kerlan RK, Golden JA, Gordon RL: Management of recurrent airway strictures in lung transplant recipients using AERO covered stents. J Vasc Interv Radiol 2010;21:1900-1904.

15 Dutau H, Musani AI, Plojoux J, Laroumagne S, Astoul P: The use of self-expandable metallic stents in the airways in the adult population. Expert Rev Respir Med 2014;8:179-190.

16 Gaissert HA, Grillo HC, Wright CD, Donahue DM, Wain JC, Mathisen DJ: Complication of benign tracheobronchial strictures by self-expanding metal stents. J Thorac Cardiovasc Surg 2003;126:744-747.
17 Noppen M, Stratakos G, D’Haese J, Meysman M, Vinken W: Removal of covered self-expandable metallic airway stents in benign disorders: indications, technique, and outcomes. Chest 2005; 127:482-487.

18 Galluccio G, Lucantoni G, Battistoni P, Paone G, Batzella S, Lucifora V, Dello Iacono R: Interventional endoscopy in the management of benign tracheal stenoses: definitive treatment at long-term follow-up. Eur J Cardiothorac Surg 2009;35:429-433.

19 Dalar L, Karasulu L, Abul Y, Özdemir C, Sökücü SN, Tarhan M, Altin S: Bronchoscopic treatment in the management of benign tracheal stenosis: choices for simple and complex tracheal stenosis. Ann Thorac Surg 2016; 101:1310-1317.

20 Martinez-Ballarin JI, Diaz-Jimenez JP, Castro MJ, Moya JA: Silicone stents in the management of benign tracheobronchial stenoses. Tolerance and early results in 63 patients. Chest 1996;109:626-629.

21 Dutau H, Cavailles A, Fernandez-Navamuel I, Breen DP: Tracheal compression in a patient with Marfan's syndrome-associated tracheomegaly treated by an XXL stent: the largest diameter airway stent ever placed in a previously undescribed airway condition. Respiration 2009;77:97-101.

22 Plojoux J, Laroumagne S, Vandemoortele T, Astoul PJ, Thomas P, Dutau H: Management of benign dynamic "A-shape" tracheal stenosis: a retrospective study of 60 patients. Ann Thorac Surg 2015;99:447-453.
Self-Expandable Metallic Stents in Benign Airway Stenosis
Respiration 2017;93:430-435 